\title{
INVESTIGATION OF THE HYDRODYNAMIC PROCESSES OF A CENTRIFUGAL PUMP IN A GEOTHERMAL SYSTEM
}

\author{
Marijonas Bogdevičius ${ }^{1}$, Jolanta Janutèniené ${ }^{2}$, Rimantas Didžiokas ${ }^{3}$, \\ Saulius Razmas ${ }^{4}$, Viktor Skrickij ${ }^{5}$, Paulius Bogdevičius ${ }^{6}$ \\ ${ }^{1,5,6}$ Dept of Transport Technological Equipment, Vilnius Gediminas Technical University, Lithuania \\ ${ }^{2,4}$ Dept of Mechanical Engineering, Klaipeda University, Lithuania \\ ${ }^{3}$ Mechatronics Science Institute, Klaipèda University, Lithuania
}

Submitted 9 October 2014; resubmitted 20 March 2015; accepted 20 April 2015; published online 29 March 2016

\begin{abstract}
The hydrodynamic and thermodynamic processes of geothermal well extraction are investigated and presented in this paper. The paper presents mathematical models for a multi-level centrifugal pump and pipeline system. The mathematical models were used to evaluate gas (nitrogen) emission in water and its effects on hydrodynamic processes. Experimental studies and mathematical modelling showed that the gas content of the fluid increases the pressure and flow pulsations within a centrifugal pump. The variation in the height of the liquid column in extraction has an influence on characteristics of the multistage centrifugal pump used in wells.
\end{abstract}

Keywords: well; geothermal water; multi-level centrifugal pump; physicochemical properties; mathematical models; transportation.

\section{Introduction}

Various investigations and analyses centred on the design and optimisation of the equipment used in geothermal power plants are done.

This research mainly focuses on the investigation of the flow of fluid inside a centrifugal pump, design and geometry of an impeller blade, pump exploitation and fluid parameters.

The most frequent approach to these kinds of problems is 3D modelling of the flow of fluid in a pump.

Various authors have already investigated problems of this kind. Some of them (Asuaje et al. 2005) performed the simulation of the 3D impeller flow and 3D quasi-unsteady flow to assess deviations in the results obtained, due to the usage of different turbulence models.

Other authors (Barrio et al. 2010) used NavierStokes equations for three-dimensional unsteady flow modelling in a geothermal pump. Unsteady flow inside a centrifugal pump was investigated by Stickland et al. (2000).

Shojaeefard et al. (2012) performed a numerical $3 \mathrm{D}$ flow simulation of a centrifugal pump together with an experimental investigation to assess the influence of geometrical parameters of the pump on its overall performance. Another paper describes the use of numerical and experimental analysis methods to investigate the dependence of the performance of a deep-well centrifugal deep well pump on the size of pump impeller outlet (Shi et al. 2013).

An approach involving a physical model in conjunction with a numerical model is presented in the paper by Yu et al. (2010). The authors investigated the flow of fluid and heat in a pipeline system under various operating conditions. García et al. (2002) used a similar approach. They analysed the influence of a non-condensable gas on the flow parameters of a geothermal system by using results acquired from a numerical analysis and experiments performed on a physical model of the system.

Aksoy (2007) analysed pump-setting depths in a liquid-dominated geothermal system. The author found that the most important parameters for determining the capacity and setting depth of a downhole pump were flow performance, non-condensable gas concentration, and temperature.

Bogdevičius et al. (2013b) analysed a hydrodynamic system, in which the gas content of the fluid exceeded 
a $2 \%$ boundary. This research presents a universal mathematical model of a real geothermal system and takes into account the impact of the gas content present in a geothermal fluid on the productivity of the entire geothermal system.

This paper aims to describe the hydrodynamic processes of a geothermal system using differential equations, solved using numerical methods. It is important to determine the steady state of the system and transient processes. The paper presents a universal mathematical model of a multi-level centrifugal pump.

In addition, the paper determines the hydrodynamics processes and takes into account the impact of the gas content of the geothermal fluid. The gas content has an impact on the productivity of a geothermal system and especially, at the stages of the multi-level centrifugal pump and in a vertical pipe.

\section{Mathematical Model of a Deep Centrifugal Pump}

\subsection{Physical Properties of Fluid}

Geothermal water behaviour depending on the pressure and volume of gas evolution was determined in experimental studies (Bogdevičius et al. 2013b).

The density of the liquid and gas mixture is:

$$
\rho=(1-\varepsilon) \rho_{S}+\varepsilon \rho_{g},
$$

where: $\rho_{S}-$ the density of water,

$$
\rho_{S}=\left(\frac{p+B_{\mathrm{H}_{2} \mathrm{O}}}{A_{\mathrm{H}_{2} \mathrm{O}}}\right)^{\frac{1}{K_{\mathrm{H}_{2} \mathrm{O}}}} \text {, }
$$

where: $p$ - pressure; $A_{\mathrm{H}_{2} \mathrm{O}}, B_{\mathrm{H}_{2} \mathrm{O}}, K_{\mathrm{H}_{2} \mathrm{O}}$ - coefficients,

$$
\begin{aligned}
& A_{\mathrm{H}_{2} \mathrm{O}}=1.00147663 \cdot 10^{-19} ; \\
& B_{\mathrm{H}_{2} \mathrm{O}}=12.858987 \cdot 10^{6} ; \\
& K_{\mathrm{H}_{2} \mathrm{O}}=7.15 ; \\
& \rho_{g}-\text { the density of gas (nitrogen, } N_{2} \text { ): } \\
& \rho_{g}=\frac{p}{Z(p, T) R T},
\end{aligned}
$$

where: $Z$ - the compressibility factor; $R$ - the gas constant; $T$ - temperature; $\varepsilon$ - the relative volume of gas:

$$
\varepsilon=\frac{V_{g}}{V}=\varepsilon(p)
$$

where: $V_{g}$ - the volume of gas; $V$ - the total volume of fluid.

The time derivate of fluid density is equal:

$$
\dot{\rho}=(1-\varepsilon) \dot{\rho}_{S}+\varepsilon \dot{\rho}_{g}-\left(\rho_{g}-\rho_{S}\right) \dot{\varepsilon}=a_{p} \dot{p}+a_{T} \dot{T},
$$

where: $a_{p}, a_{T}$ - coefficients as a function of pressure and temperature;

$$
\begin{aligned}
& \dot{\rho}_{S}=\frac{d \rho_{S}}{d t} ; \\
& \dot{\rho}_{g}=\frac{d \rho_{g}}{d t} ; \\
& \dot{T}=\frac{d T}{d t} ; \\
& \dot{\varepsilon}=\frac{d \varepsilon}{d t} .
\end{aligned}
$$

The bulk modulus elasticity of the fluid is equal:

$$
K=\frac{K_{S}}{1-\varepsilon+\varepsilon \frac{K_{S}}{\gamma p}}
$$

where: $K_{S}$ - the bulk modulus elasticity of water; $\gamma$ - the ratio of specific heat.

\subsection{Dynamic Model of the Deep Centrifugal Pump}

The main equations that describes the work of a geothermal system are pressure, flow rate and temperature changes.

Description of system processes rests on the following assumptions:

- deep well productivity depends on the pressure in the depths;

- geothermal fluid volume that is between centrifugal pump blades are resolved into concentrated volumes;

- heat exchange takes place between the geothermal fluid and the surrounding environment (the pipe wall);

- geothermal fluid is compressible, and compressibility depends on the gas pressure and temperature;

- between concentrated geothermal fluid volumes are evaluated pressure losses;

- generated pump pressure depends on the blade geometry and the angular speed of the impeller.

Changes in the liquid and gas mixture pressure and temperature in the input of the $k$-step volume are described by the equations:

$$
\begin{aligned}
& \dot{p}_{K, 0}=\frac{1}{C_{K, 0}}\left(Q_{K-1, N+1}-\sum_{L=1}^{N L} Q_{K, L, 1}\right) ; \\
& \dot{T}_{K, 0}=\frac{1}{\rho_{K, 0} V_{K, 0}}\left(Q_{K-1, N+1}-\sum_{L=1}^{N L} Q_{k, L, 1} T_{k, L, 1}\right)- \\
& \frac{A_{S, K, 0}}{\rho_{K, 0} V_{K, 0} C_{p}} h_{K, 0}\left(T_{K, 0}-T_{K, 0, \infty}\right),
\end{aligned}
$$

where: $C_{K, 0}=\frac{V_{K, 0}}{K\left(p_{K, 0}\right)} ; V_{K, 0}-$ volume of the liquid and gas mixture; $K\left(p_{K, 0}\right)$ - the bulk modulus elasticity; $Q_{K-1, N+1}, Q_{K, L, 1}$ - the inlet and outlet flow rates of the fluid; $T_{K-1, N+1}, T_{K, L, 1}$ - the inlet and outlet temperatures of the fluid; $h_{K, 0}$ - heat transfer coefficient; $A_{S, K, 0}-$ the surface area; $C_{p}$ - the specific heat; $T_{K, M, \infty}$ - the temperature; $N L$ - the number of blades.

Changes in the fluid pressure and temperature in the $k$-stage and the $L$-blade, $j$-th volume are described by the equations:

$$
\begin{aligned}
& \dot{p}_{k, L, j}=\frac{1}{C_{k, L, j}}\left(Q_{k, L, j}-Q_{k, L, j+1}\right) \\
& \dot{T}_{k, L, j}=\frac{1}{\rho_{, k, L, j} V_{k, L, j}}\left(Q_{k, L, j} T_{k, L, j-1}-Q_{k, L, j+1} T_{k, L, j}\right)- \\
& \frac{A_{k, L, j}}{\rho_{k, L, j} V_{k, L, j} C_{p}} h_{k, L, j}\left(T_{k, L, j}-T_{k, L, j, \infty}\right) .
\end{aligned}
$$




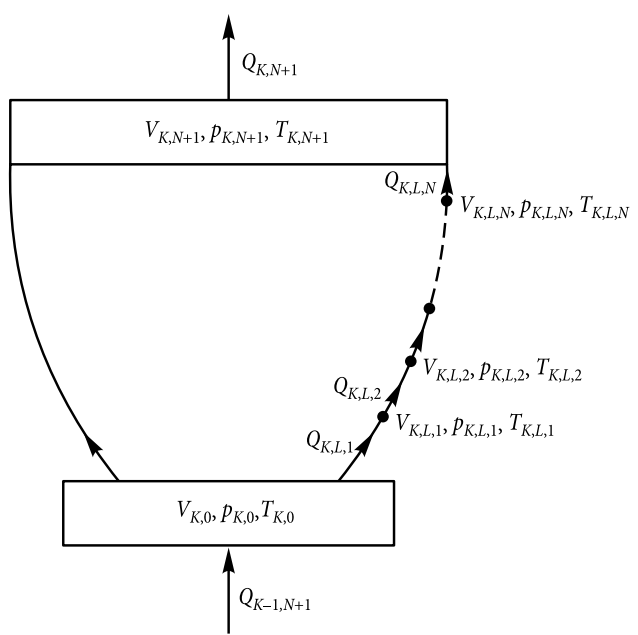

Fig. 1. Computational scheme of the pump stage

Fig. 1 represents the discrete computational scheme of one stage of the 16-stage centrifugal pump. Equations are solved using the concentrated parameter method, conducting geometrical characteristic and other properties of each blade.

The flow of the fluid and gas mixture in the $k$-stage and the $L$ - blade, $j$-th volume are described by the equations:

$$
\begin{aligned}
& \dot{Q}_{k, L, j}=\frac{1}{m_{k, L, j}}\left(p_{k, L, j-1}-p_{k, L, j}-\right. \\
& \frac{1}{2} \rho_{k, L, j} \zeta_{k, l, j}\left(\frac{Q_{k, L, j}}{A_{k, L, j}}\right)^{2} \operatorname{sign}\left(Q_{k, L, j}\right)- \\
& \left.g \rho_{k, L, j} L_{k, L, j} \sin \alpha_{k, L, j}\right)+\frac{1}{2} \rho_{k, L, j} \dot{\varphi}_{k}^{2} R_{k, l, j}^{2} \cos \left(\alpha_{k, L, j}\right)- \\
& \left.g \rho_{k, L, j} L_{k, L, j} \sin \alpha_{k, L, j}+\frac{1}{2} \rho_{k, L, j} \dot{\varphi}_{k}^{2} R_{k, l, j}^{2} \cos \left(\alpha_{k, L, j}\right)\right)- \\
& \frac{Q_{k, L, j}}{\rho_{k, L, j}} \dot{\rho}_{k, L, j},
\end{aligned}
$$

where: $R_{k, L, j}$ - the radius before the investigating volume element; $\alpha_{k, L, j}$ - the angle between the liquid flow rate and radius; $\dot{\varphi}_{k}-k$-th step of angular velocity; $m_{k, l, j}=\rho_{k, l, j} \frac{L_{k, l, j}}{A_{k, l, j}} ; L_{k, l, j}, A_{k, l, j}$ - the length and crosssectional area of the element; $\zeta_{k, l, j}$ - the coefficient of pressure losses,

$$
\zeta_{k, l, j}=\zeta_{\text {local }, k, l, j}+\lambda_{k, l, j} \frac{L_{k, l, j}}{d_{k, l, j}},
$$

where: $\zeta_{\text {local }, k, l, j}$ - coefficient of local losses; $d_{k, l, j}$ - the diameter of blade; $\lambda_{i, j, k}$ - the coefficient of friction between the liquid flow and the blade surface is determined by the dependence (Bogdevičius et al. 2013b):

$$
\lambda_{i, j, k}(\operatorname{Re})=2\left(\left(\frac{8}{\operatorname{Re}}\right)^{12}+\frac{1}{(A+B)^{1.5}}\right)^{\frac{1}{12}} .
$$

Pressure, flow and temperature equations are written in matrix form:

$$
\left\{\dot{X}_{k, L, j}\right\}=\left[A_{k, L, j}\right]^{-1}\left\{F_{k, L, j}\left(X_{k, L, j}\right)\right\},
$$

where:

where:

$$
\begin{aligned}
& {\left[A_{k, L, j}\right]^{-1}=\left[\begin{array}{ccc}
1 & 0 & 0 \\
0 & 1 & 0 \\
-\frac{Q_{k, L, j}}{\rho_{k, L, j}} a_{p, k, L, j} & \frac{Q_{k, L, j}}{\rho_{k, L, j}} a_{T, k, L, j} & 1
\end{array}\right] ;} \\
& \left\{X_{k, L, j}\right\}^{T}=\left\{p_{k, L, j} \quad T_{k, L, j} \quad Q_{k, L, j}\right\} ; \\
& \left\{F_{k, L, j}\left(X_{k, L, j}\right)\right\}=\left\{\begin{array}{l}
f_{1} \\
f_{2} \\
f_{3}
\end{array}\right\},
\end{aligned}
$$

$$
\begin{aligned}
& f_{1}=\frac{1}{C_{k, L, j}}\left(Q_{k, L, j}-Q_{k, L, j+1}\right) ; \\
& f_{2}=\frac{1}{\rho_{, k, L, j} V_{k, L, j}}\left(Q_{k, L, j} T_{k, L, j-1}-Q_{k, L, j+1} T_{k, L, j}\right)- \\
& \frac{A_{k, L, j}}{\rho_{k, L, j} V_{k, L, j} C_{p}} h_{k, L, j}\left(T_{k, L, j}-T_{k, L, j, \infty}\right) ; \\
& f_{3}=\frac{1}{m_{k, L, j}}\left(p_{k, L, j-1}-p_{k, L, j}-\frac{1}{2} \rho_{k, L, j} \zeta_{k, l, j}\left(\frac{Q_{k, L, j}}{A_{k, L, j}}\right)^{2} \times\right. \\
& \operatorname{sign}\left(Q_{k, L, j}\right)-g \rho_{k, L, j} L_{k, L, j} \sin \alpha_{k, L, j}+ \\
& \left.\frac{1}{2} \rho_{k, L, j} \dot{\varphi}_{k}^{2} R_{k, l, j}^{2} \cos \left(\alpha_{k, L, j}\right)\right) .
\end{aligned}
$$

The liquid and gas mixture pressure and temperature in general $k$-th step output volume is described by the equations:

$$
\begin{aligned}
& \dot{p}_{K, M}=\frac{1}{C_{K, M}}\left(\sum_{l=1}^{N} Q_{K, l, M}-Q_{K, 1}\right) ; \\
& \dot{T}_{K, M}=\frac{1}{\rho_{K, M} V_{K, M}}\left(\sum_{L=1}^{N L} Q_{K, l, M} T_{k, l, j-1}-Q_{K, N+1}\right)- \\
& \frac{A_{S, K, M}}{\rho_{K, M} V_{K, M} C_{p}} h_{K, M}\left(T_{K, M}-T_{K, M, \infty}\right),
\end{aligned}
$$

where: $h_{K, M}$ - the heat transfer coefficient; $V_{K, M}$ - the volume of the liquid and gas mixture; $A_{S, K, M}$ - the cross section area; $C_{p}$ - the specific heat; $T_{K, M, \infty}$ - the ambient temperature.

The fluid flow which is flowing out from the general output volume of the $k$-th stage is equal:

$$
\begin{aligned}
& \dot{Q}_{K, 1}=\frac{1}{m_{K, 1}}\left(p_{K, M}-p_{K+1,0}-\right. \\
& \left.\frac{1}{2} \rho_{K, 1} \zeta_{K, 1}\left(\frac{Q_{K, 1}}{A_{K, 1}}\right)^{2} \operatorname{sign}\left(Q_{K, 1}\right)-g \rho_{K, 1} L_{K, 1}\right)- \\
& \frac{Q_{K, 1}}{\rho_{K, 1}} \dot{\rho}_{K, 1} .
\end{aligned}
$$




\subsection{Mathematical Model of the Mechanical Part of the Deep Centrifugal Pump}

The deep centrifugal pump consists of a 16-stage, where each stage has nine blades. The deep centrifugal pump is submerged $300 \mathrm{~m}$ down in the well. In creating a mathematical model of the deep centrifugal pump, the dynamic characteristics of the asynchronous motor, mechanical relations between the steps, each blade's geometry, moments of inertia of the masses of each step, pressure and velocity effects on each blade, and forces acting on each blade are estimated.

Change in the asynchronous motor torque is described by the equation:

$$
\dot{M}_{R}=u c_{V}\left(\omega_{V 0}-u \dot{\varphi}_{R}\right)-d_{V} M_{R}
$$

where: $c_{V}, d_{V}$ - parameters of the system; $\omega_{v 0}$ - angular velocity of the asynchronous engine; $u$ - the gear ratio.

A dynamic model of the mechanical system of the deep centrifugal pump is presented in Fig. 2.

Equation system of the mechanical system of the deep centrifugal pump:

$$
\left(\begin{array}{l}
I_{1} \ddot{\phi}_{1}=M_{R}-k_{12}\left(\phi_{1}-\phi_{2}\right)-c_{12}\left(\dot{\phi}_{1}-\dot{\phi}_{2}\right)-M_{1} ; \\
I_{2} \ddot{\phi}_{2}=-k_{12}\left(\phi_{2}-\phi_{1}\right)-c_{12}\left(\dot{\phi}_{2}-\dot{\phi}_{1}\right)- \\
-k_{23}\left(\phi_{2}-\phi_{3}\right)-c_{23}\left(\dot{\phi}_{2}-\dot{\phi}_{3}\right)-M_{2} ; \\
\cdots \\
I_{k} \ddot{\phi}_{k}=-k_{k-1, k}\left(\phi_{k}-\phi_{k-1}\right)-c_{k-1, k}\left(\dot{\phi}_{k}-\dot{\phi}_{k-1}\right)- \\
-k_{k, k+1}\left(\phi_{k}-\phi_{k+1}\right)-c_{k, k+1}\left(\dot{\phi}_{k}-\dot{\phi}_{k+1}\right)-M_{k} ; \\
\cdots \\
I_{M} \ddot{\phi}_{M}=-k_{M-1, M}\left(\phi_{M}-\phi_{M-1}\right)- \\
-c_{M-1, M}\left(\dot{\phi}_{M}-\dot{\phi}_{M-1}\right)-M_{M},
\end{array}\right.
$$

where: $I_{k}$ - mass inertia moment of $k$-th stage; $k_{k-1, k}$, $c_{k-1, k}$ - stiffness and damping coefficient between $(k-1)$ th and $k$-th masses; $M_{k}$ is resistance torque.

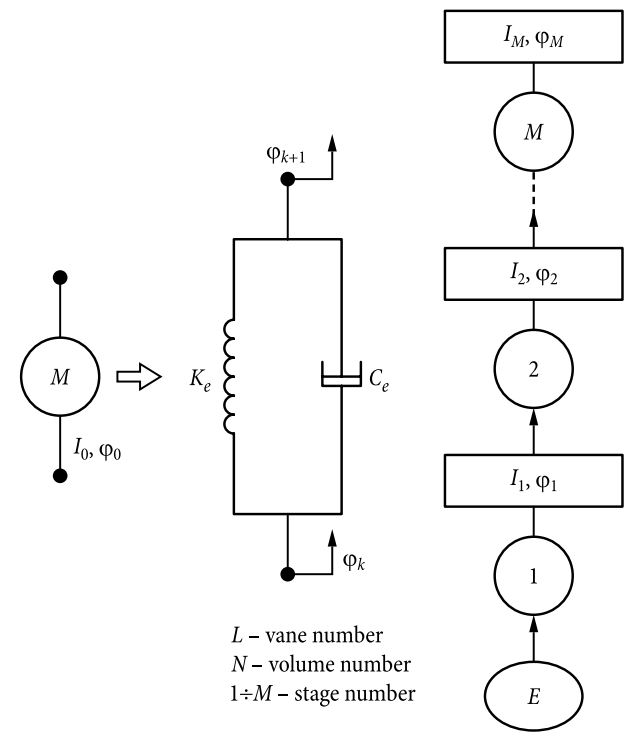

Fig. 2. Dynamic model of the mechanical system of the deep centrifugal pump
In matrix form:

$$
[M]\{\ddot{\varphi}\}+[C]\{\dot{\varphi}\}+[K]\{\varphi\}=\{F\},
$$

where: $\{\varphi\},\{\dot{\varphi}\},\{\ddot{\varphi}\}-$ the vectors of the angle, angular velocity, and angular acceleration:

$$
\{\varphi\}=\left[\varphi_{1}, \varphi_{2}, \ldots, \varphi_{M}\right]
$$

$[M],[C],[K]$ - mass, damping, stiffness matrix; $\{F\}-$ force vector.

The system of equations of the mechanical system is described by the first order differential equations:

$$
\left\{\dot{X}_{1}\right\}=\left[A_{1}\right]\left\{X_{1}\right\}+\left\{B\left(X_{1}, p, Q, T\right)\right\},
$$

where: $\left\{X_{1}\right\}$ - the vector of the unknown of the mechanical system,

$$
\begin{aligned}
& \left\{X_{1}\right\}^{T}=\left[M_{R}, \varphi_{1}, \varphi_{2}, \ldots, \varphi_{M}, \dot{\varphi}_{1}, \dot{\varphi}_{2}, \ldots, \dot{\varphi}_{M}\right]= \\
& {\left[\left\{X_{11}\right\}^{T},\left\{X_{12}\right\}^{T},\left\{X_{13}\right\}^{T}\right] \text {; }} \\
& {[A]=\left[\begin{array}{ccc}
{\left[A_{11}\right]} & {[0]} & {\left[A_{13}\right]} \\
{[0]} & {[0]} & {[E]} \\
{\left[A_{31}\right]} & -[M]^{-1}[K] & -[M]^{-1}[C]
\end{array}\right] ;} \\
& {\left[A_{11}\right]=\left[-d_{V}\right] \text {; }} \\
& {\left[A_{13}\right]=\left[0,-u c_{V}, 0, \ldots, 0\right] \text {; }} \\
& {\left[A_{31}\right]^{T}=[1,0, \ldots, 0] \text {; }} \\
& {[M]=\operatorname{diag}\left(I_{1}, I_{2}, \ldots, I_{M}\right) \text {; }} \\
& \{B\}^{T}=\left[u c_{V} \omega_{V, 0},\{0\}^{\mathrm{T}},\{\mathrm{F}\}^{\mathrm{T}}\right] \text {. }
\end{aligned}
$$

\subsection{Mathematical Model of the Hydraulic System of the Deep Centrifugal Pump}

Characteristics of the pump describe its operation when pumping fluid, but these characteristics change when water contains dissolved gases (Bogdevičius et al. 2014).

The deep centrifugal pump is immersed to a depth of $H_{0}$ (Fig. 3). The water column height is variable when the well's fluid and the gas mixture is pumped from the depths $\left(H_{\text {well }}=1100 \mathrm{~m}\right)$.

Higher liquid column height, the lower volume of gas in the liquid so that the pump can operate more stably.

In the time of transitional process if the flow of the pump is higher than the in the depths then high of water column start changing, and the process becomes unstable.

The equations of the water column height variation are equal to:

$$
\dot{H}_{\text {in }}=\frac{1}{A_{\text {well }, 1}}\left(Q_{\text {well }}-Q_{\text {in }} \operatorname{sign}\left(Q_{\text {in }}\right)\right),
$$

where: $Q_{\text {well }}$ - flow of geothermal fluid, 


$$
\begin{aligned}
& Q_{\text {well }}=\frac{A_{\text {wel }}}{\sqrt{\zeta_{\text {well }}}} \sqrt{\frac{2}{\rho_{\text {depth }}}\left|p_{\text {depthl }}-p_{\text {well }}\right|} \mid \times \\
& \operatorname{sign}\left(p_{\text {depth }}-p_{\text {well }}\right),
\end{aligned}
$$

where: $Q_{i n}$ - the fluid flow entering the centrifugal pump; $\rho_{\text {depth }}$ - the density of the geothermal water at the bottom of the well; $A_{\text {well }}$ - the cross-section of the filter; $\zeta_{w e l l}$ - the pressure loss coefficient; $p_{\text {depth }}$ - the pressure at the bottom of the well; $p_{\text {well }}$ - the pressure at the bottom above the filter:

$$
p_{\text {well }}=\rho_{\text {well }} g\left(H_{\text {well }}-H_{0}+H_{\text {in }}\right)+p_{\text {gas }},
$$

where: $\rho_{\text {well }}$ - the liquid and the gas density at the bottom above the filter; $p_{\text {gas }}$ - pressure of the gas (nitrogen, $\mathrm{N}_{2}$ ) extracted at the well top,

$$
p_{\text {gas }}=C_{\text {gas }} V_{\text {gas }}^{-\gamma}
$$

where: $V_{g a s}$ - the volume of gas; $\gamma$ - adiabatic rate; $C_{g a s}-$ the constant.

Fluid flow entering the pump is described by the equation:

$$
\begin{aligned}
& \dot{Q}_{i n}=\frac{1}{m_{i n}}\left(p_{i n}-p_{1}-p_{i n H}-\right. \\
& \left.\frac{1}{2} \rho_{i n} \zeta_{i n}\left(\frac{Q_{i n}}{A_{\text {in }}}\right)^{2} \cdot \operatorname{sign}\left(Q_{i n}\right)\right)-\frac{Q_{i n}}{\rho_{\text {in }}} \dot{\rho}\left(p_{i n}, T_{i n}\right),
\end{aligned}
$$

where: $L_{i n}, A_{\text {in }}$ - the inlet pipe length and cross-section area; $\zeta_{\text {in }}$ - the pressure loss coefficient of the pump in the inlet pipe,

$$
\begin{aligned}
& \zeta_{\text {in }}=\zeta_{\text {local }, \text { in }}+\lambda_{\text {in }}\left(\operatorname{Re}, \Delta_{n}\right) \frac{L_{\text {in }}}{D_{\text {in }}} ; \\
& m_{\text {in }}=\rho\left(p_{\text {in }}\right) \frac{L_{\text {in }}}{A_{\text {in }}} ; \\
& p_{\text {in }, \mathrm{H}}=g \rho_{\text {in }} L_{i n} .
\end{aligned}
$$

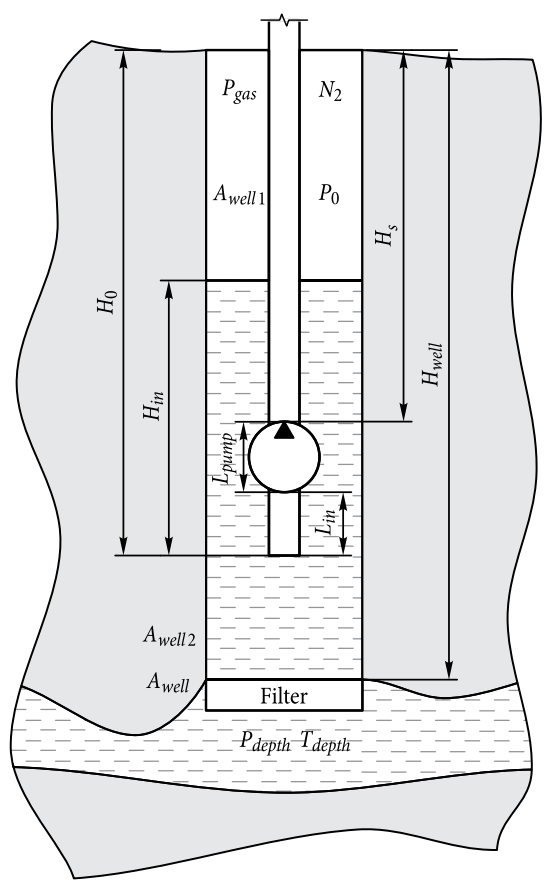

Fig. 3. Scheme of the extraction well

\section{Numerical Analysis of the Deep Centrifugal Pump}

\subsection{The Input Data}

The deep centrifugal pump consists of 16 steps, where each step consists of 9 blades, and each blade is divided into ten discrete liquid and gas volumes. The rotation frequency of the asynchronous motor is $43 \mathrm{~Hz}$.

The initial water level (from the centrifugal pump suction end to the top of the well) is $H_{\text {in }}(t=0)=270 \mathrm{~m}$, $H_{\text {well }}=1130 \mathrm{~m} ; H_{0}=300 \mathrm{~m}$.

The inside diameter of the pipe $=7.5$ inches and the initial pressure of the gas is $p_{\text {gas }}=0.25 \mathrm{MPa}$. The time steps of integration are $\Delta t=5 \cdot 10^{-6} \mathrm{~s}$.

It is analysed the hydrodynamic process of the geothermal system at start time, then the pressure at the end of pipe gradually increases and after some time stabilizes.

After stabilized processes the pressure at the end of the pipe periodically changes.

The second case of load the pipeline is selected to check how to change hydrodynamic processes when is different load pressure.

Because gas release from the geothermal water depends on the pressure, then the fluctuation of pressure in different places of geothermal systems can cause fluctuations the hydrodynamic parameters.

The load pressure of the extraction pipe varies according to the law:

$$
\begin{aligned}
& p_{\text {load }}=p_{\text {load, } \max }\left(1-\exp \left(-\alpha_{P} t\right)\right)+ \\
& p_{\text {ampl }} \sin \left(2 \pi f_{p}\left(t-t_{1}\right)\right) H\left(t-t_{1}\right),
\end{aligned}
$$

where: $p_{\text {load,max }}$ - the maximum load pressure; $\alpha_{P}-$ coefficient; $p_{a m p l}, f_{p}$ - load pressure amplitude and frequency; $t_{1}$ - time when load pressure changes according to harmonic function.

\subsection{Results of the Numerical Analysis}

As mentioned above, at the start of the system, the liquid column height varies, thus changing the pressure and volume of gas in the water.

When the value of pressure is low in the inlet of the deep centrifugal pump, the amount of gas is higher. Consequently, the liquid is more compressible, the productivity of deep centrifugal pump is lower, and the transition process is longer. Fig. 4.

The water column height variation is shown in

Fig. 5 shows pressure variations in different centrifugal pump stages when load pressure gradually increases and stabilizes and Fig. 6 gives flow variations.

Fig. 5 shows that the change of the graph transition process pressure is not the same at different stages of the deep centrifugal pump.

At each stage of the deep stage centrifugal pump, pressure pulsations generate in the vertical pipe. Then, the transition process lasts longer.

Fig. 6 shows that the flow rate varies periodically at the levels of the deep centrifugal pump. The maximum range of flow rate variation is about 4 seconds. In this case, the frequency of change of the flow rate is about $0.25 \mathrm{~Hz}$. 


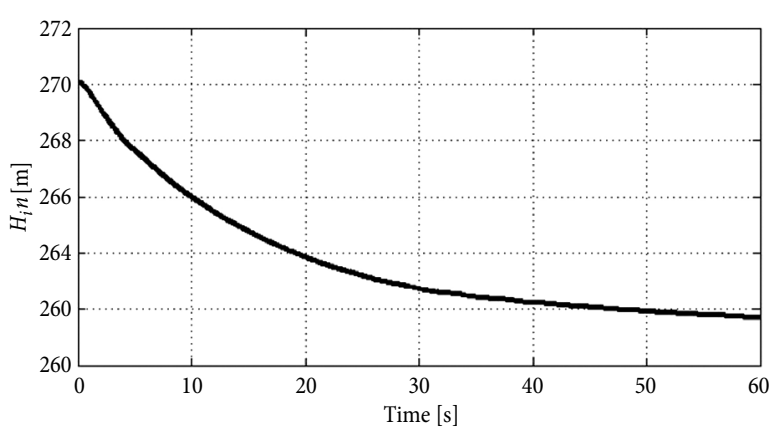

Fig. 4. Water column height variation

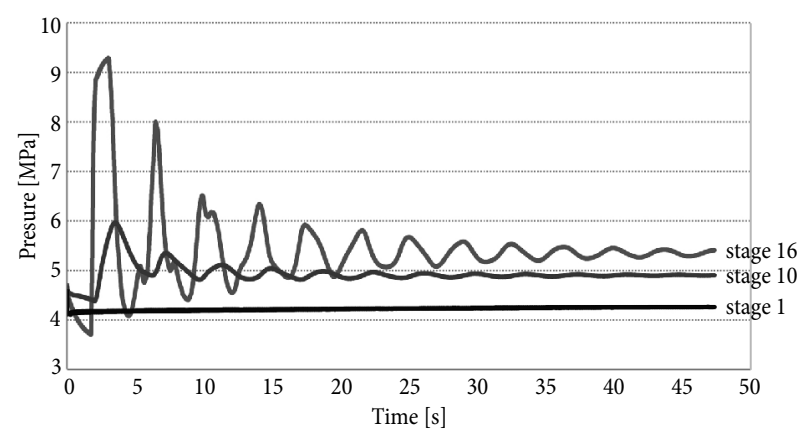

Fig. 5. Dependencies of pressure in the 1st, 10th and 16th stages of centrifugal pump over time
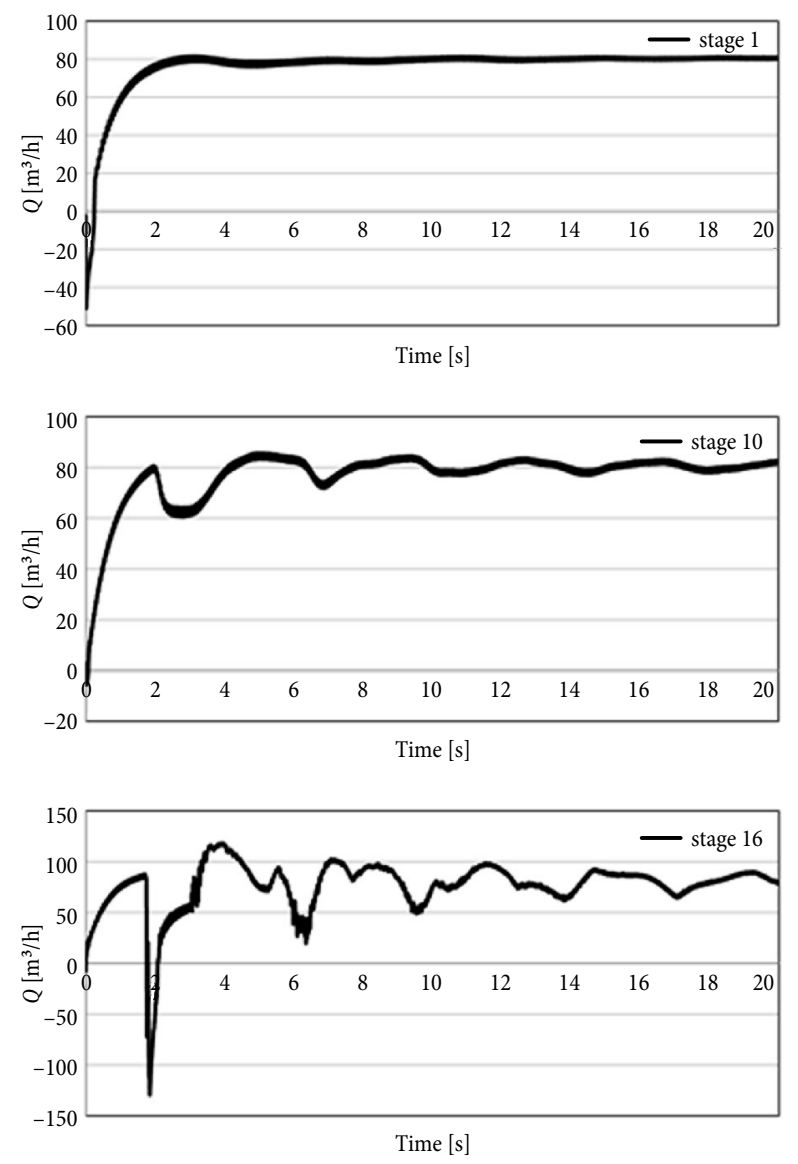

Fig. 6. Dependencies of flow variations in 1st, 10th and 16th stages of centrifugal pump over time
Analysis of the deep centrifugal pump-pipe of a geothermal system shows that the lowest natural frequency of the system is less than $1 \mathrm{~Hz}$ (Bogdevičius et al. 2013a).

The pressure drop in the vertical pipe at different depths is shown in Fig. 7 and flow variation in Fig. 8.

As we can see, the pressure and the flow rate are variables in the output of the pump during the transitional process. Pressure fluctuations decrease in the upper part of pipes because geothermal water gets substantially compressible and suppresses pressure pulsation better.

Dependencies of the relative volume of gas $\varepsilon(t)$ in the vertical pipe at different depths are shown in Fig. 9, when $t>20 \mathrm{~s}$ load pressure varies periodically.

The selected load pressure frequency $f_{p}$ is close to the natural frequency of the geothermal system.

Dependencies of flow variations in the vertical pipe at different depths when load pressure - varies periodically over time are shown in Fig. 10.

As can be seen from Fig. 10, when the depth is lower, a variation of flow amplitude is higher. This can be explained by the decrease of depth and increases in the amount of dissolved gases in geothermal water (Fig. 9).

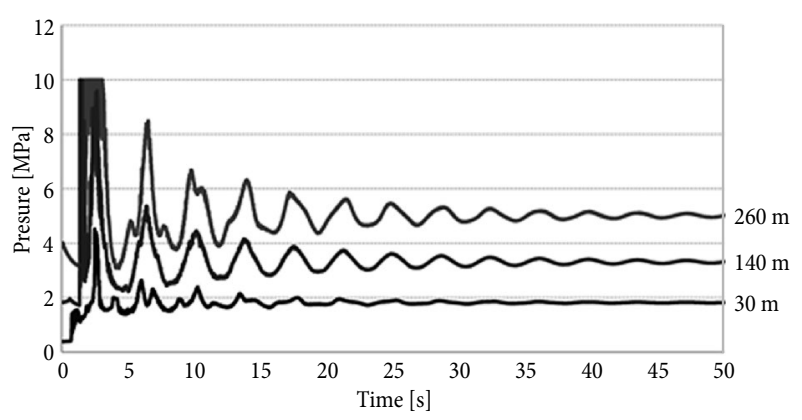

Fig. 7. Dependencies of pressure drop in the vertical pipe at different depths over time
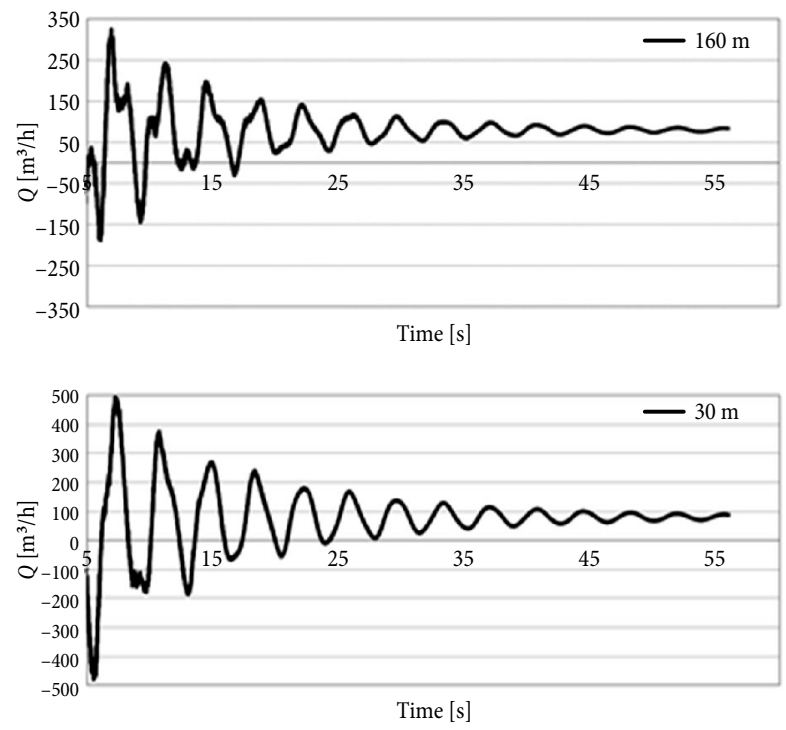

Fig. 8. Dependencies of flow variations in the vertical pipe at different depths over time 

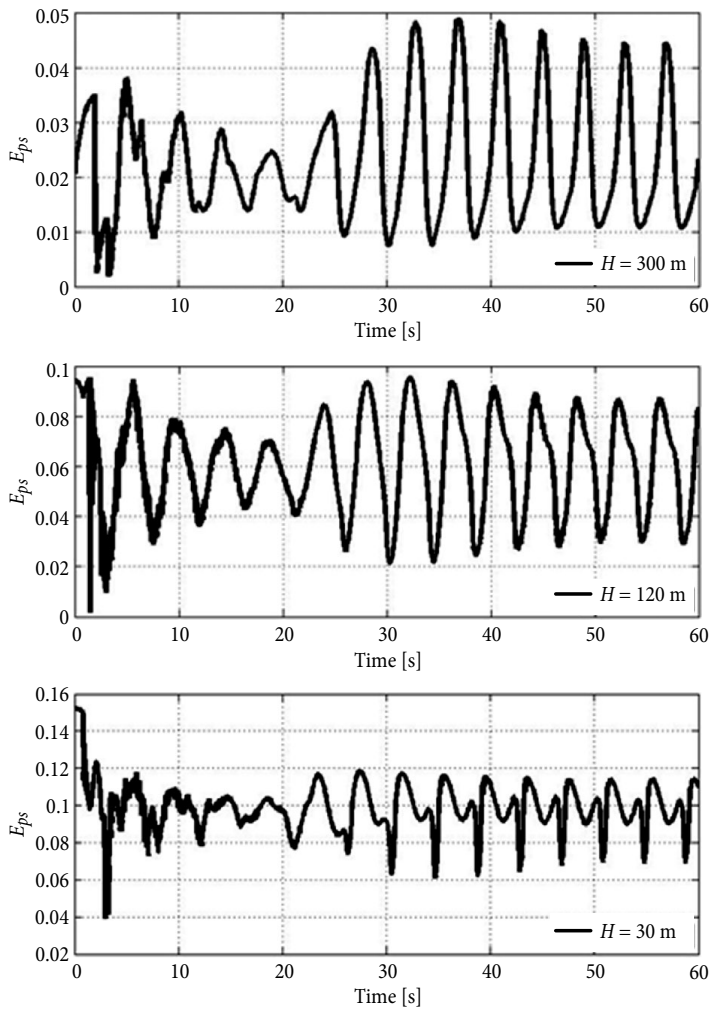

Fig. 9. Dependencies of the relative volume of gas $\varepsilon(t)$ in the vertical pipe at different depths when load pressure $p_{\text {load }}$ varies periodically: $\mathrm{a}-H=300 \mathrm{~m} ; \mathrm{b}-H=120 \mathrm{~m} ; \mathrm{c}-H=30 \mathrm{~m}$ (when $p_{\text {load, } \text {, } a x}=1.0 \mathrm{MPa}, p_{\text {ampl }}=0.25 \mathrm{MPa}, f_{p}=0.25 \mathrm{~Hz}$ )
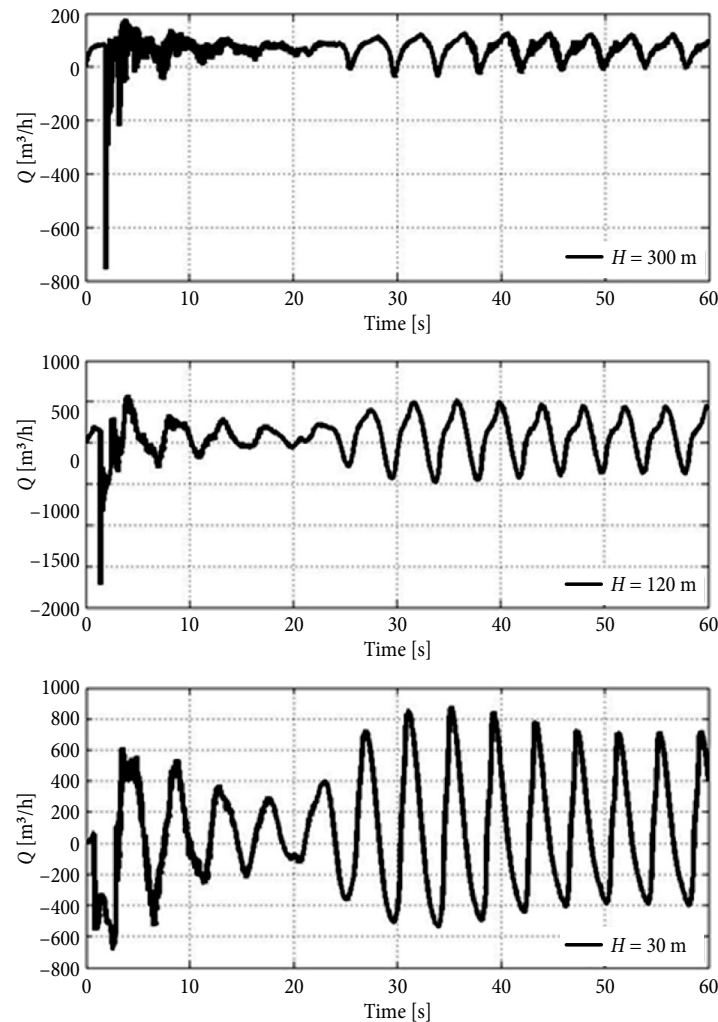

Fig. 10. Dependencies of a variation of flow in the vertical pipe at different depths when load pressure $p_{\text {load }}$ varies periodically: $\mathrm{a}-H=300 \mathrm{~m} ; \mathrm{b}-H=210 \mathrm{~m} ; \mathrm{c}-H=120 \mathrm{~m} ; \mathrm{d}-H=30 \mathrm{~m}$ (when $p_{\text {load, } \text { max }}=1.0 \mathrm{MPa} ; p_{\text {ampl }}=0.25 \mathrm{MPa}, f_{p}=0.25 \mathrm{~Hz}$ )
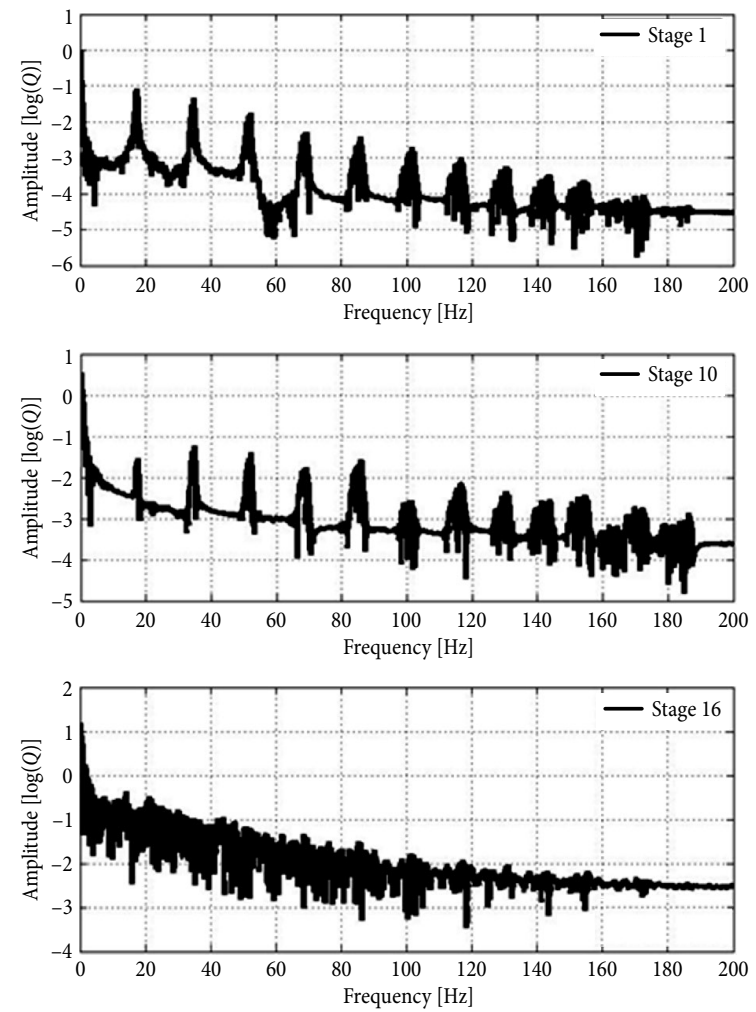

Fig. 11. Spectrum of the amplitude of flow in the 1st, 10 th, and 16th stages of the centrifugal pump, when $p_{\text {load, } \max }=1.0 \mathrm{MPa}, p_{\text {ampl }}=0.25 \mathrm{MPa}, f_{p}=0.25 \mathrm{~Hz}$
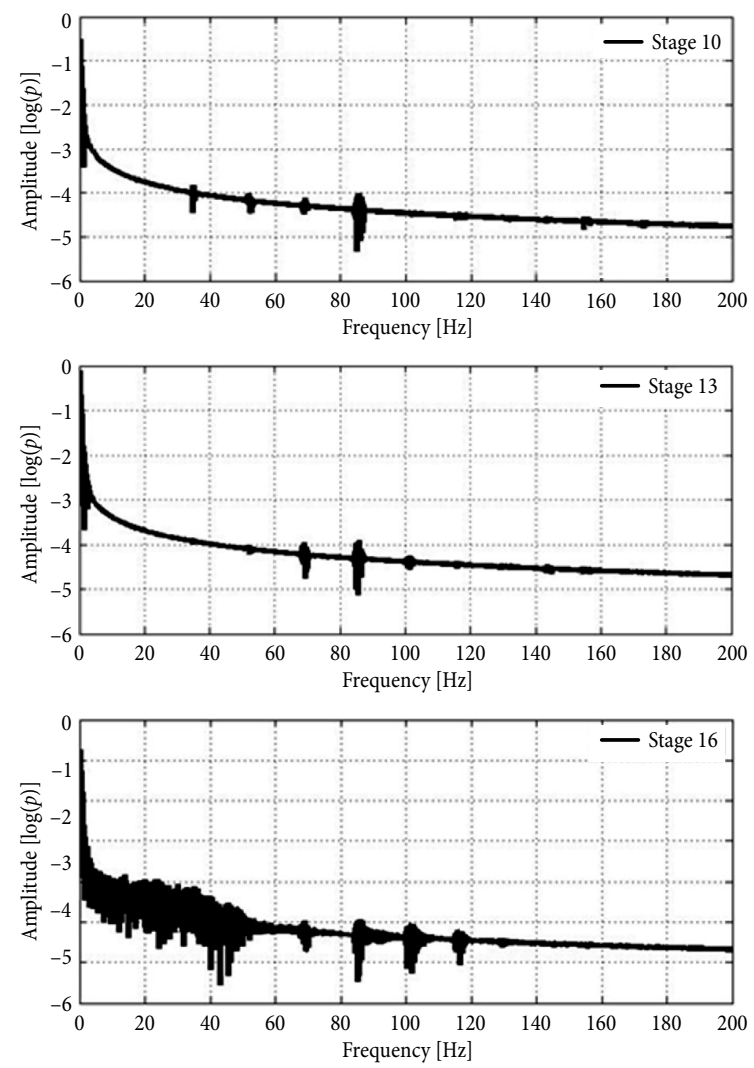

Fig. 12. Spectrum of the amplitude of pressure in the 1st, 5th, 10th, 13th and 16th stages of the centrifugal pump, when $p_{\text {amol }}=0.25 \mathrm{MPa}, f_{p}=0.25 \mathrm{~Hz}$ 
Compressibility of geothermal water at different depths is different and causes flow fluctuations in the geothermal system.

The spectra of flow of the deep centrifugal pump, when load pressure varies periodically, are shown in Fig. 11.

From the spectra of amplitude flow, we can see that in the higher stage of the centrifugal pump the variation of flow amplitude decreases. We can see a repeated harmonics at the frequency of $18 \mathrm{~Hz}$, the first natural frequency of the geothermal system is low (less than $1 \mathrm{~Hz}$ ).

The spectra of pressure and the flow rate show the change in the amount of gas, which causes significant flow pulsations.

\section{Conclusions}

The mathematical model of geothermal well extraction using a multi-stage centrifugal pump was developed. The basis of this model established the geothermal pipeline parameters of the centrifugal pump. A gradual increase in the pressure load in the pipeline up to a certain maximum value $(1.0 \mathrm{MPa})$ periodically changes the parameters of geothermal water flow. The lowest frequency is about $0.25 \mathrm{~Hz}$.

The investigation established that the volume of gas increases the pressure and flow pulsations in the deep centrifugal pump and causes changes in the pressure and flow spectra amplitudes.

From a centrifugal pump characteristic curve $p=p(Q)$ it can be found that the increasing load of pipeline pressure decreases flow of centrifugal pump.

The change in the pressure load in the pipeline from $0.25 \mathrm{MPa}$ to $1.50 \mathrm{MPa}$ reduces the flow of the deep centrifugal pump: $\Delta Q_{\text {pump }}=13.69 \mathrm{~m}^{3} / \mathrm{h}$ at a frequency of the centrifugal pump with an electric engine $43 \mathrm{~Hz}$ and $\Delta Q_{\text {pump }}=17.35 \mathrm{~m}^{3} / \mathrm{h}$ at the electric motor frequency of $50 \mathrm{~Hz}$.

When the geothermal system is under a varying periodic pressure load, all geothermal parameters (pressure, flow, temperature, the relative volume of gas) in different places of pipeline vary periodically and have different amplitudes.

In pipeline low-pressure zones, the gas distinguishes and the compressibility of the geothermal water increases. Compressibility of the geothermal water increases flow oscillations, which reduces the efficiency of the pipeline and the cavitation can appear (in the deep centrifugal pump and in the pipeline).

Therefore, in order to rationally exploit geothermal system should be selected such parameters as the immersion deep of deep centrifugal pump, the rotation frequency of the electric engine of centrifugal pump, the load pressure in the pipeline taking in the account physicochemical properties of the geothermal water.

\section{Acknowledgments}

This work was supported by the Research Council of Lithuania within the framework of the project 'Simulation software and the investigation of thermo-hydrodynamic processes in the geothermal loop', project No. MIP-090/2012.

\section{References}

Aksoy, N. 2007. Optimization of downhole pump setting depths in liquid-dominated geothermal systems: a case study on the Balcova-Narlidere field, Turkey, Geothermics 36(5): 436-458.

http://dx.doi.org/10.1016/j.geothermics.2007.07.003

Asuaje, M.; Bakir, F.; Kouidri, S.; Kenyery, F.; Rey, R. 2005. Numerical modelization of the flow in centrifugal pump: volute influence in velocity and pressure fields, International Journal of Rotating Machinery 2005(3): 244-255. http://dx.doi.org/10.1155/IJRM.2005.244

Barrio, R.; Parrondo, J.; Blanco, E. 2010. Numerical analysis of the unsteady flow in the near-tongue region in a volutetype centrifugal pump for different operating points, Computers \& Fluids 39(5): 859-870. http://dx.doi.org/10.1016/j.compfluid.2010.01.001

Bogdevičius, M.; Janutènienè, J.; Razmas, S.; Drakšas, M.; Didžiokas, R.; Nikitin, V. 2014. Investigation of hydrodynamic processes in geothermal plant, in 11th World Congress on Computational Cechanics (WCCM XI), 20-25 July 2014, Barcelona, Spain, 6: 7361-7371.

Bogdevičius, M.; Janutènienè, J.; Didžiokas, R.; Nikitin, V.; Razmas, S.; Drakšas, M. 2013a. Investigation into the stability of hydrodynamic processes in the depth centrifugal pump and pipeline system, in TRANSBALTICA 2013: Proceedings of the 8th International Scientific Conference, 9-10 May 2013, Vilnius, Lithuania, 1-4.

Bogdevičius, M.; Janutėnienè, J.; Razmas, S.; Drakšas, M. 2013b. Mathematical modeling of hydrodynamic processes in geothermal plant, in V International Conference on Computational Methods for Coupled Problems in Science and Engineering: Coupled Problems 2013, 17-19 June 2013, Ibiza, Spain, 1-7.

García, A.; Espinosa-Paredes, G.; Barragán, R. M. 2002. Effect of non-condensable gases on the flow of water and steam in geothermal wells, Geofísica Internacional 41(4): 377-383.

Shi, W.; Zhou, L.; Lu, W.; Pei, B.; Lang, T. 2013. Numerical prediction and performance experiment in a deep-well centrifugal pump with different impeller outlet width, Chinese Journal of Mechanical Engineering 26(1): 46-52. http://dx.doi.org/10.3901/CJME.2013.01.046

Shojaeefard, M. H.; Tahani M.; Ehghaghi, M. B.; Fallah Ardeshir, H.; Beglari, M. 2012. Numerical study of the effects of some geometric characteristics of a centrifugal pump impeller that pumps a viscous fluid, Computers \& Fluids 60: 61-70. http://dx.doi.org/10.1016/j.compfluid.2012.02.028

Stickland, M. T.; Scanlon, T. J.; Blanco-Marigorta, E.; Fernández-Francos, J.; González-Pérez, J.; Santolaria-Morros, C. 2000. Numerical flow simulation in a centrifugal pump with impeller-volute interaction, in Proceedings of the ASME 2000 Fluids Engineering Division Summer Meeting, 11-15 June 2000, Boston, Massachusetts, 1-7.

Yu, B.; Li, C.; Zhang, Z.; Liu, X.; Zhang, J.; Wei, J.; Sun, S.; Huang, J. 2010. Numerical simulation of a buried hot crude oil pipeline under normal operation, Applied Thermal Engineering 30(17-18): 2670-2679. http://dx.doi.org/10.1016/j.applthermaleng.2010.07.016 